\title{
El convenio arbitral en la nueva ley general de Arbitraje, ley 26572
}

Fernando Cantuarias Salaverry

Hace unos días ha sido publicada la ley 26572 -ley general de Arbitraje- (en adelante simplemente LGA), la cual modifica, en poco más de tres años, el marco normativo aplicable a la práctica arbitral en nuestro país'.

La nueva LGA introduce saludables mejoras respecto de muchas de las instituciones reguladas por la anterior ley arbitral ${ }^{2}$. Uno de estos cambios fundamentales está referido a la adopción de la figura del convenio arbitral, institución que en nuestra opinión permitirá el desarrollo de la práctica arbitral en el país.

El presente artículo tiene como misión explicar cuáles han sido las consecuencias de haber regulado en nuestro país la dualidad cláusula compromisoria-compromiso arbitral, cuáles fueron las fallas de la anterior

\footnotetext{
1 La nueva ley general de Arbitraje - ley 26572- ha sido publicada el 5 de enero último, habiendo entrado en vigencia al día siguiente. Deroga la anterior ley general de Arbitraje -decreto ley 25935- aunque esta última disposición seguirá rigiendo los procesos arbitrales iniciados antes de la vigencia del nuevo dispositivo legal, de conformidad con la quinta Disposición Complementaria y Transitoria de la ley 26572.

2 Si bien el decreto ley 25935 significó un gran avance si lo comparamos con las vetustas normas sobre arbitraje contenidas en el Código de Procedimientos Civiles y Código Civil, este cuerpo legal cometió algunos errores, los cuales motivaron la necesidad de promulgar un nuevo texto normativo a poco más de tres años de su expedición. Sobre el tema recomendamos leer: Cantuarias S., Fernando, y Manuel Diego Aramburu Y., El arbitraje en el Perú: desarrollo actual y perspectivas futuras, Fundación M. J. Bustamante de la Fuente, Cultural Cuzco S.A., Lima, 1994, pp. 63 y ss.; CANTUARIas S., Fernando, «Los árbitros en la ley general de Arbitraje: algunas reflexiones", Revista del Foro, n." 2, Colegio de Abogados de Lima, Lima, 1993, pp. 75 y ss.; Cantuarias Salaverry, Fernando, "Algunos de los principales cambios que contiene el anteproyecto de la nueva ley general de Arbitraje», Gaceta Juridica, n..$^{\circ} 13$, Lima, 1995, pp. 57-A y ss.; y Cantuarias Salaverry, Fernando, "Algunas modificaciones que deben hacerse con urgencia a las disposiciones sobre arbitraje doméstico contenidas en la ley general de Arbitrajen, Themis, Revista de Derecho, n. ${ }^{\circ} 31$, Lima, 1995, pp. 37 y ss.
} 
ley general de Arbitraje en esta materia y cómo operará el sistema con la nueva LGA.

\section{La cláusula compromisoria y el compromiso arbitral}

Hasta antes de la dación de la anterior LGA, nuestro ordenamiento jurídico siempre distinguió dos tipos de acuerdos arbitrales: la cláusula compromisoria y el compromiso arbitral ${ }^{3}$.

La cláusula compromisoria, como bien indica Matthies, «es un acuerdo de voluntades que se celebra casi siempre conjuntamente con uno o varios negocios jurídicos y en donde las partes declaran de antemano su decisión de someter cualesquiera controversias que pudieren resultar de la interpretación o ejecución de dichos negocios, a la exclusiva jurisdicción de árbitros. Se le da el nombre de cláusula porque generalmente va inserta como una de muchas cláusulas de que consta el o los negocios que liga a dos o más partes. Sin embargo, nada obsta para que la cláusula compromisoria sea escriturada en documento separado [...]” ${ }^{4}$.

Por su parte, Cárdenas ${ }^{5}$ define al compromiso arbitral como el acuerdo mediante el cual "dos o más partes acuerdan voluntariamente que una controversia determinada, existente entre ellas, materia o no de un juicio, sea resuelta por uno o más terceros (el o los árbitros), a los que designan, sometiéndose expresamente a su jurisdicción y decisión". El contrato de compromiso arbitral puede otorgarse como consecuencia de haberse celebrado previamente una cláusula compromisoria o aun sin la existencia de ésta; pero sólo cuando ha surgido una controversia entre las partes (a diferencia de la cláusula compromisoria, que se suscribe cuando no existe pleito).

\footnotetext{
En el Perú esta distinción fue tratada de manera explícita en el Código Civil de 1984 (arts. 1906 y 1909). El Código de Procedimientos Civiles de 1912 se refirió de manera indirecta a la cláusula compromisoria en el artículo 556.

GARro, Alejandro M., "Enforcement of Arbitration Agreements and Jurisdiction of Arbitral Tribunals in Latin America" (en adelante simplemente "Enforcement"), Journal of International Arbitration, vol. 1, n. ${ }^{\circ} 4,1989$, p. 312 . Explica el autor que esta distinción también se encuentra presente en los siguientes ordenamientos jurídicos latinoamericanos: Código Civil y Comercial Federal argentino (art. 739), Código Civil del Brasil (art. 1038), Código de Comercio de Colombia (art. 2011), Código de Procedimientos Civiles del Ecuador (art. 1014), Código Judicial de Panamá (art. 1733) y Código de Procedimientos Civiles de Venezuela (art. 503).

MATTHIES T., Félix Roland, Arbitrariedad y arbitraje: un análisis de la normatividad sobre arbitraje de Derecho privado en Venezuela (pendiente de publicación), pp. 15-16.

Cárdenas Q., Carlos, Delia Revoredo (compiladora), Código Civil, Exposición de Motivos y comentarios, t. VI, 1985, p. 641.
} 
A partir de estas definiciones, verifiquemos que la única diferencia sustancial entre la cláusula compromisoria y el compromiso arbitral es el hecho de que, mientras al momento de suscribirse una cláusula compromisoria no hay conflicto, cuando se celebra un compromiso arbitral ya existe controversia.

Sin embargo, esta sola diferencia, que en nuestra opinión carece de sustantividad, genera efectos muy distintos, ya que las partes que han suscrito una cláusula compromisoria tendrán obligatoriamente que otorgar un nuevo contrato -compromiso arbitral-como paso previo al arbitraje, no pudiendo en consecuencia acudir a arbitrar directamente sus controversias.

Como veremos a continuación, este efecto, diverso de la cláusula compromisoria y del compromiso arbitral, resulta siendo funesto.

\subsection{Problemas que se presentan en la ejecución de los contratos de cláusula compromisoria y compromiso arbitral}

Todas las legislaciones a las que hemos hecho referencia anteriormente ${ }^{6}$, disponen que si las partes han pactado un acuerdo arbitral antes de que nazca la controversia (cláusula compromisoria), cuando ésta se presente tendrán necesariamente que otorgar un nuevo contrato -compromiso arbitral-como paso previo ineludible para derivar el conflicto al arbitraje y evitar de esa manera la intervención del Poder Judicial.

Fijémonos que mientras la cláusula compromisoria se suscribe "[...] cuando todavía no media pleito alguno; por el contrario, las partes se encuentran en lo mejor de sus relaciones y deciden que, si algún día se produce un desentendimiento entre ellas, recurrirán a un arbitraje antes que a un juicio [...] " ${ }^{7}$, cuando la ley les obliga a otorgar el compromiso arbitral, las partes «se encuentran en un estado de ánimo radicalmente diferente de aquel que prevalecía cuando suscribieron la cláusula compromisoria. Ya no están en el mejor momento de sus relaciones, sino en el peor; y muy probablemente existe un estado de guerra sorda o manifiesta entre ellas. No es, pues, la ocasión ideal para pedirles un nuevo acuerdo de voluntades" ${ }^{8}$.

Ver supra, cita n." 3.

Trazegnies GRANDA, Fernando de, "Los conceptos y las cosas, vicisitudes peruanas de la cláusula compromisoria y del compromiso arbitral", El arbitraje en el Derecho latinoamericano y españoh, libro homenaje a Ludwick Kos Rabcewitz, Cultural Cuzco S.A., Lima, 1989, p. 549.

${ }_{x} \quad$ Ibid., p. 549. 
Sin embargo, las legislaciones que mantienen la distinción bajo estudio exigen a las partes la suscripción del compromiso arbitral, aun cuando saben que ello será imposible de cumplir en la generalidad de los casos (si no en todos) ${ }^{9}$, ya que obviamente «la parte que está en falta tiene todos los incentivos para no suscribir dicho contrato: sabe que si va al arbitraje, lo más probable es que pierda en un corto plazo (a diferencia del Poder Judicial, donde la resolución del conflicto tomará varios de años en el mejor de los casos) y, al tratarse de árbitros expertos en la materia, posiblemente el laudo reconocerá en favor de la otra parte las prestaciones debidas (a diferencia de los jueces, los cuales muchas veces son poco técnicos en temas contractuales y/o comerciales, lo que puede llevar a que se otorguen o reconozcan menores beneficios en favor de la parte que no está en falta). ¿Qué hará entonces la parte deudora? Pues tratará de dilatar a lo máximo la suscripción del compromiso arbitral, planteando condiciones inaceptables y, como sucede en la gran mayoría de los casos, no otorgará el compromiso arbitral» ${ }^{10}$.

¿Qué salida nos ofrecen las legislaciones que obligan a la suscripción del compromiso arbitral, cuando una de las partes se niega a otorgarlo? Pues nada más y nada menos que el tener que acudir al Poder Judicial, para que, luego de un largo proceso, sea el juez quien en rebeldía otorgue el famoso compromiso arbitral, imponga el nombre de todos los árbitros y determine además las materias que las partes podrán someter a conocimiento de los árbitros ${ }^{11}$.

BOND, Stephen R., "How to Draft an Arbitration Clause", Journal of International Arbitration, vol. 6, n." 2, 1989, p. 67. En este artículo publicado en su calidad de secretario general de la Cámara de Comercio Internacional (CCI), Bond señala: "Experience makes clear that if you wish to have arbitration, an arbitration clause must be incorporated into the contract or otherwise become part of the written agreement establishing the commercial relationship between you and your business partner. Of the 237 cases submitted to the ICC Court last year, only four of them resulted from a compromis, that is, an agreement to submit an already-existing dispute to arbitration. The other 233 cases arose from clauses compromissoires, that is, an arbitration clause agreeing to submit future disputes to arbitration. The reasons are obvious. Once a dispute arises, in most instances the parties can no longer agree on anything, including how to resolve their dispute."

1" Cantuarias S., Fernando, "Cláusula compromisoria y compromiso arbitral vs. convenio arbitral", ADSUM Revista Jurídica, n." 8, Lima, 1993, p. 92.

"Hay que añadir además los costos que genera la propia actividad jurisdiccional, la posibilidad de que la parte en falta dilate el procedimiento, y, lo más grave aún, la posibilidad de que el juez se niegue a otorgar el bendito compromiso arbitral, con lo que de esa manera la controversia se quedará definitivamente en el Poder Judicial.

FARGosı, Alejandro, Commercial Arbitration in Argentina. Commercial and Labor Arbitration in Central America, editado por Alejandro M. Garro, American Bar Association, Nueva York, 1991, p. 21. "Any potential debtor who faces litigation has the option of submitting the dispute to the courts, where ordinary proceedings last about two years, or submitting the 
Así, las partes que querían evitar la intervención del Poder Judicial ${ }^{12}$, por imposición de este absurdo sistema terminarán en manos de los jueces para que éstos nombren a todos los árbitros ${ }^{13}$, y lo que es más grave aún, para que determinen de antemano lo que se debe arbitrar y lo que quedará exclusivamente en manos del aparato jurisdiccional del Estado $^{14}$.

Luego de haber descrito este absurdo y penoso procedimiento por el que tienen que desfilar todos aquellos que quieran arbitrar sus controversias en aquellos Estados que mantienen la distinción entre cláusula compromisoria y compromiso arbitral, no es de extrañar que, como ha sucedido en el Perú, "[...] el arbitraje no haya tenido mayor utilidad [...]. Es significativo que en siete años, entre 1968 y 1974 (no disponemos de estadísticas de otros períodos), solamente haya habido diez arbitrajes, tres de derecho y siete por árbitros arbitradores ${ }^{15}$.

Es cierto que la poca utilización del arbitraje está íntimamente ligada a su limitada difusión y al desconocimiento por parte de sus potenciales usuarios (abogados, comerciantes, etc); pero también es cierto que gran parte de su inutilidad estriba en la pobre regulación que se ha dado respecto de dicha institución, en especial en lo que se refiere a la distinción entre cláusula compromisoria y compromiso arbitral.

case to arbitration, where in a maximun of six months the matter is likely to be resolved [...] from the perspective of a debtor in default, the financial option is to pay the eventual debt within six months, including real interest, or to pay it two or three years later, thus obtaining the additional benefit of disposing of the money at a reduced interest rate. Except for the potential debtor who acts according to strict ethical standards, or who has discovered the value of a good business reputation, most will prefer to profit at the expense of their creditors, in spite of having to pay the costs of the trial. A debtor benefits from the inflation in a two year trial despite the eventual payment of court costs and expenses."

12 CaIvano, Roque J., Arbitraje: su eficacia como sistema alternativo de resolución de conflictos, Ad-Hoc SRL., Buenos Aires, 1993, p. 135. “Importa una verdadera paradoja que las partes deban recurrir a la justicia -a la misma justicia que quisieron evitar al pactar el arbitraje- y que ello sea para poner en funcionamiento el sistema elegido, sin haber podido siquiera entrar al tratamiento de las cuestiones litigiosas."

13. Las partes al suscribir la cláusula compromisoria consideran, entre otros factores, la ventaja que significa que terceras personas de su confianza (nombradas por ellas) o extrañas (pero designadas por un tercero por ellas nominado para tal fin) resuelvan sus potenciales disputas, en vez de que sea un juez impuesto por el Estado el que proceda con tal misión. Sin embargo, dentro de este sistema, en la generalidad de los casos será justamente el juez el encargado de imponer a las partes el nombre de todos los árbitros.

Nadie discute que los árbitros sólo pueden conocer y fallar respecto de aquellos temas que las partes les han delegado expresamente. Sin embargo, la pregunta que nos hacemos es: ¿Por qué debe ser el juez el que previamente tenga que determinar la extensión de la controversia? ¿Por qué no dejar este tema a las partes y a los árbitros, al menos en una primera instancia?

Trazegnies Granda, Fernando de, op. cit., pp. 550-551. 
Por ello compartimos plenamente las palabras de Trazegnies ${ }^{16}$, quien considera que la distinción entre cláusula compromisoria y compromiso arbitral convierte al arbitraje "en algo absolutamente inoperante", agregando que, "no es de extrañar que, en estas condiciones, el arbitraje no haya tenido mayor utilidad en el país».

\title{
1.2 Origen y necesidad de eliminar la distinción
}

\author{
No existiendo justificación alguna para mantener la distinción bajo es- \\ tudio, resulta importante el preguntarse cómo y por qué apareció y si es \\ posible reemplazarla por otra figura que no cause tantos problemas.
}

16 Ibid., p. 551. Adicionalmente debemos indicar que la doctrina tradicional plantea hasta cuatro justificaciones para mantener esta discutible distinción. La primera especialmente propuesta por Ogayár y Ayllón (citado por Cárdenas Quirós, Carlos, op. cit., p. 674), el cual considera que no es posible acudir directamente al arbitraje teniendo un simple acuerdo arbitral suscrito antes de que nazca la controversia (cláusula compromisoria), ya que la materia controvertida no está debidamente determinada; por lo que de permitirse a las partes el acudir directamente al arbitraje, ello significaría una renuncia genérica a la jurisdicción natural del Poder Judicial. Obviamente esta justificación es inaceptable, ya que cuando se suscribe un acuerdo arbitral conjuntamente con un contrato principal o en forma independiente pero haciendo referencia a una relación jurídica, la materia controvertida está debidamente determinada a roda controversia que se presente en la interpretación y/o ejecución de esa relación jurídica. Por tanto, no puede hablarse de renuncia genérica cuando el propio acuerdo arbitral determina su ámbito de aplicación.

TRAZEGNiES GRANDA, Fernando de, op. cit., p. 552, hace saber que una segunda justificación consiste en que si bien al momento de otorgarse la cláusula compromisoria la materia controvertida está debidamente determinada en su máxima extensión, "los árbitros no pueden operar sin una definición previa de los términos [exactos] de la controversia por las partes; es preciso decirles el punto controvertido sobre el cual tienen que pronunciarsem, por lo que resultaría necesario que se otorgue el compromiso arbitral. Sin embargo, el propio Trazegnies se apura en negar esta afirmación, ya que para determinar los términos precisos de la controversia "no es preciso un segundo acuerdo formal de voluntades sino que bastaría una presentación unilateral de las respectivas posiciones ante el árbitro, de la misma manera como sucede en un juicio con la demanda y su contestación. Esto simplificaría notablemente el procedimiento y evitaría tener que recurrir al Poder Judicial, aun antes de comenzado el arbitraje, para definir lo que va a ser materia de arbitraje."

También se da como justificación el hecho de que normalmente cuando se suscribe una cláusula compromisoria las partes no suelen nombrar a los árbitros, razón por la cual, cuando surge la controversia, resulta necesario otorgar el compromiso arbitral para identificar a los miembros del tribunal arbitral. Esta justificación también carece de valor, pues si bien al momento de otorgarse la cláusula compromisoria no se suele nombrar a los árbitros, este hecho no tiene por qué conllevar la suscripción de un nuevo contrato, ya que si no existen árbitros nombrados, pues bastará que las partes los designen (por ejemplo, mediante un simple intercambio de comunicaciones), o que el tercero nominador (una institución arbitral, por ejemplo) proceda al nombramiento, o, a falta, proceda a la designación el juez o alguna institución gremial y/o profesional. Y punto. 
Como demostraremos a continuación, a diferencia de lo que muchos juristas creen o nos quieren hacer creer, la distinción bajo estudio no tiene un origen legal, sino una explicación en la historia de Francia.

Como señala Von Mehren ${ }^{17}$, durante los primeros años de la Revolución francesa el acceso al arbitraje se llevó a cabo sin reserva alguna. Sin embargo, como bien indica Garro ${ }^{18}$, pasados algunos años y ante la reacción en contra de la ideología revolucionaria, comenzó a crecer la hostilidad del Poder Judicial hacia el arbitraje. Esta hostilidad tuvo como punto culminante el fallo de la Corte Suprema francesa del 10 de julio de 1843, en el caso seguido entre L'Alliance contra Prunier, en el que se declaró expresamente nulo el pacto por el cual las partes acuerdan arbitrar cualquier futura controversia -cláusula compromisoria $-{ }^{19}$.

Esta reacción del supremo tribunal de justicia francés poco tuvo que ver con consideraciones jurídicas y más con criterios políticos y de manifiesta hostilidad y temor hacia el arbitraje. Von Mehren explica que el fallo demostró el temor de los jueces de que si la cláusula compromisoria era permitida, ésta sería pactada por la generalidad de los individuos, quitándole de esa manera poder a los magistrados ${ }^{20}$.

Obviamente este fallo tuvo como única finalidad la de impedir que las partes acudieran a arbitrar sus controversias, ya que la experiencia había demostrado en ese momento, como ahora, que en la generalidad de los casos las partes acuerdan arbitrar antes de que se presente el conflicto, mientras que sólo en un número reducido de casos se dispone arbitrar cuando las controversias ya son existentes ${ }^{21}$

Finalmente, el jurista argentino Horacio GRIGERA NAÓN, "Arbitration in Latin America: Overcoming traditional hostility", Arbitration International, vol. 5, n. ${ }^{\circ}$ 2, 1989, pp. 146-148, justifica la distinción bajo estudio, ya que en su opinión el solo hecho de tener que sentarse en la mesa cara a cara para suscribir el compromiso arbitral y determinar de esa manera la materia controvertida, el nombre de los árbitros y cualquier otro tema vinculado al fururo arbitraje, posibilita que las partes cooperen de forma amistosa en la determinación de todo lo relativo al arbitraje e incluso lleguen a transar sus controversias.

Obviamente esta visión romántica e idealista sobre la función que cumpliría la celebración del compromiso arbitral choca frontalmente con la realidad. En vez de ser un trámite que permita la cooperación de las partes, la obligación de otorgar el compromiso arbitral se convierte en la generalidad de los casos en un entorpecimiento del arbitraje, ya que la parte deudora hará todo lo posible para no suscribirla, terminando esta "guerra sucia" ante los tribunales de justicia.

17 VON MEHREN, Arthur Taylor, “International Commercial Arbitration: The contribution of the French Jurisprudencem, Louisiana Law Review, vol, 46, n. ${ }^{\circ}$, Louisiana State University, 1986, pp. 1046 y ss.

is Garro, Alejandro M., "Enforcement", op. cit., p. 314.

1. Von Mehren, Arthur Taylor, op. cit., p. 1946; Garro, Alejandro M., "Enforcement", op. cit., p. 314

20 Von Mehren, Arthur Taylor, op. cit., p. 1047.
21 Ver supra, cita n." 9. 
Luego del fallo los juristas se encargaron de explicar "jurídicamente" la distinción entre el pacto previo -cláusula compromisoria- y el acuerdo suscrito una vez surgida la controversia -compromiso arbitral-, dando a entender mediante la aplicación de un sinnúmero de teorías, que existían entre ambos contratos grandes diferencias. Sin embargo, en la realidad, los juristas se olvidaron de que la distinción poco o nada tenía que hacer con el Derecho, sino simplemente con una visión hostil hacia el arbitraje.

Con los años esta actitud hostil hacia el arbitraje ha ido cambiando poco a poco. Es así que a partir de los primeros años del siglo XX, y en especial luego de la segunda guerra mundial, el arbitraje ha vuelto a constituirse en el mecanismo idóneo de resolución de conflictos entre particulares, principalmente valioso en el intercambio comercial internacional.

Desgraciadamente la casi totalidad de las legislaciones arbitrales latinoamericanas han copiado y mantenido inmutable la distinción bajo estudio como si fuera sagrada, despreocupándose, no sabemos si de forma intencional, de sus funestas consecuencias prácticas ${ }^{22}$.

Obviamente, para impulsar el renacimiento o, mejor dicho, el nacimiento efectivo de la práctica arbitral en Latinoamérica y especialmente en el Perú, resulta necesario acabar con la distinción entre cláusula compromisoria y compromiso arbitral, como una demostración palpable de que la actitud hostil hacia el arbitraje ha terminado ${ }^{23}$. Para ello, como veremos enseguida, es que justamente se creó la figura del convenio arbitral.

\section{El convenio arbitral}

En muy simples palabras, el término "convenio arbitral» no hace más que reconocer que la existencia de un acuerdo arbitral pactado antes de que nazca la controversia (cláusula compromisoria), es suficiente para que las partes puedan acudir directamente al arbitraje, sin tener que

22 Garro, Alejandro M., "Enforcement", op. cit., p. 373. "Thus, whereas in most modern arbitration statutes and international arbitration conventions the distinction between arbitral clauses and submission retains a merely theoretical value, it has been noted that in many Latin American countries the distinction remains undisturbed with devastating consequences for the development of domestic as well as international arbitration".

2.3 Caivano, Roque J., op. cit., pp. 134-135. "Si se piensa en el compromiso arbitral como una fórmula inevitable para acceder al arbitraje, estaremos generando una de las más importantes fuentes de litigios y demoras en su implementación, y uno de los más sólidos factores impeditivos para la aceptación del arbitraje como método alternativo de resolución de conflictos." 
otorgar un nuevo contrato -compromiso arbitral-. En otras palabras, mediante la aplicación de la figura del convenio arbitral, a las partes les bastará suscribir una "cláusula compromisoria" para que, sin la necesidad de suscribir otro documento, puedan derivar sus controversias al arbitraje cuando éstas se presenten ${ }^{24}$.

Según tenemos entendido, la primera referencia al convenio arbitral se dio en el ámbito internacional en el Protocolo relativo a Cláusulas de Arbitraje, adoptado en Ginebra en $1923^{25}$. Sin embargo, fue recién en 1958 cuando se adoptó el Convenio sobre Reconocimiento y Ejecución de las Sentencias Arbitrales Extranjeras, más conocido como la Convención de Nueva York de 1958, que adquirió vigencia mundial ${ }^{26}$, habiendo servido esta convención como modelo para la modernización de otros instrumentos internacionales y de muchas legislaciones domésticas ${ }^{27}$, las cuales han eliminado definitivamente la dualidad cláusula compromisoria-compromiso arbitral.

Igual sucede con la reciente legislación arbitral española de 1988, la cual, como bien indica García Rubio ${ }^{28}$, «a partir de la entrada en vigor de la nueva LA el régimen dual deja de existir, englobándose ambas instituciones, pacto y compromiso, con idénticos efectos, en el más ge-

24 SANDERS, Pieter, "Exposición en la clausura del Seminario de Arbitraje Comercial International": El arbitraje comercial en Iberoamérica, Instituto de Cooperación Iberoamericana y el Consejo Superior de las Cámaras Oficiales de Comercio, Industria y Navegación de España, Madrid, 1982, pp. 375-376. Este autor, al referirse acerca de las legislaciones arbitrales latinoamericanas, indica que «al contrario de la situación prevaleciente en el resto del mundo, la cláusula compromisoria, aunque legalmente obligatoria, necesita todavía complementarse con un compromiso, a redactar de una forma especial, una vez haya surgido una disputa. Esta situación también surgió en Francia hace unos cincuenta años, pero fue abandonada cuando la ley se cambió en 1926, de acuerdo con el Protocolo de Ginebra de 1923. Actualmente, la cláusula arbitral es suficiente por sí misma en cualquier parte; no existe la necesidad de reunir a las partes, una vez surgida una disputa, para redactar un acta de compromiso (sometimiento a arbitraje) ni de apelar a un tribunal cuando una de las partes no lo desee".

${ }_{25}$ El texto de dicho protocolo puede ubicarse en el excelente libro del Dr. Ulises MonTora AlberTl, El arbitraje comercial, Cultural Cuzco S.A., Lima, 1988, pp. 301-303.

26. El texto de la Convención puede ubicarse en el libro del Dr. Montoya, op. cit., pp. 309-314. Sobre una explicación de los antecedentes de dicha convención, recomendamos leer: Cantuarias S., Fernando, «Reconocimiento y ejecución de laudos arbitrales internacionales: la Convención de Nueva York de 1958 y la ley modelo de UNCITRAL", Themis, Revista de Derecho, n." 21, segunda época, Lima, 1992, pp. 17-24.

Así, tenemos por ejemplo al Reino Unido (Arbitration Act, 1950), Estados Unidos de América (Federal Arbitration Act de 1925 y Uniform Act), Países Bajos (Código Procesal Civil, artículo 620, según la reforma de 1972) y Bélgica (Código Procesal Civil, de acuerdo con la reforma de 1972). En Francia, la doctrina y la jurisprudencia se han encargado de reconocer el convenio arbitral.

28 Garcia Rubio, María Paz, “El convenio arbitral en la ley de arbitraje de 5 de diciembre de 1989", Revista de la Corte Española de Arbitraje, vol. V, Editorial Civitas, Madrid, 1988-1989, p. 73 . 
nérico término "convenio arbitral". La principal consecuencia de la equiparación establecida es que, a partir de la entrada en vigor de la LA, la cláusula compromisoria no necesita el complemento del compromiso para dar nacimiento al arbitraje».

\subsection{Contenido del convenio arbitral}

Hemos apreciado cómo la expresión «convenio arbitral» comprende tanto a la "cláusula compromisoria" como al "compromiso arbitral». En ese sentido, resulta pertinente el preguntarse cuál es el contenido mínimo o esencial del convenio arbitral.

En la división tradicional de cláusula compromisoria y compromiso arbitral, los elementos esenciales de ambos contratos son los siguientes:

- Cláusula compromisoria: a) El pacto mediante el cual las partes se comprometen a arbitrar sus controversias, y b) La fijación de la relación jurídica respecto de la cual se arbitrarán los futuros e inciertos conflictos.

- Compromiso arbitral: a) La identificación de las partes; b) La designación de los árbitros; c) La definición de la materia controvertida; d) La indicación del plazo para laudar, y e) La determinación del lugar donde se desarrollará el arbitraje.

De esta manera, si las partes han suscrito un contrato de cláusula compromisoria, como éste carece de la determinación de la materia controvertida y normalmente no se han nombrado a los árbitros, cuando se origine la controversia las partes deberán otorgar un compromiso arbitral, cumpliendo con los requisitos en cuanto a su contenido obligatorio.

Dentro de este contexto, ¿̇cómo es posible que se permita gracias a la creación de la figura del "convenio arbitral» que las partes con una simple cláusula arbitral acudan a arbitrar directamente sus controversias, si no se han designado a los árbitros, definido la materia controvertida, indicado el plazo para laudar y determinado el lugar del arbitraje? Pues simplemente reconociéndose que los elementos esenciales del convenio arbitral son sólo dos:

1) El compromiso inequívoco y claro de que las partes desean arbitrar sus controversias ${ }^{29}$, y

29 PARK, William W., "Arbitration of International Contract Disputes", The Business Lauyer, vol. 39, 1984, p. 1785. «Essential to a binding arbitration clause is, of course, an unambiguous and unequivocal reference to arbitration $[\ldots] . "$ 
2) La fijación de la relación jurídica respecto de la cual se arbitrarán los futuros e inciertos conflictos. Es decir, será necesario determinar respecto de qué relación jurídica se acudirá a arbitrar en caso de que se presente un conflicto entre las partes ${ }^{30}$.

Verifiquemos que ambos elementos esenciales están presentes al momento de suscribirse la "cláusula compromisoria", ya que, por un lado, la "cláusula compromisoria" implica por sí misma una renuncia a la jurisdicción natural de los jueces, y, por otro lado, en ella se determina la extensión máxima de los conflictos al fijarse la relación jurídica respecto de la cual se arbitrarán las controversias que se presenten. De esta mane$\mathrm{ra}$, independientemente de que las partes pacten un convenio arbitral antes de que nazca la controversia o cuando ésta ya exista, las partes pueden acudir directamente a arbitrar sus conflictos, sin tener que otorgar ningún otro contrato.

Otros elementos que las partes podrán pactar en cualquier momento pero cuya omisión no obligará a suscribir un nuevo contrato, son, entre otros $^{31}$ :

a) El número de los árbitros.- En caso de no existir pacto, las leyes suelen establecer supletoriamente que el número de árbitros será impar, normalmente tres.

b) La designación de los árbitros.- En caso de no haber sido designados en su oportunidad, la ley suele establecer mecanismos supletorios de nombramiento, siendo el más común aquel que establece que cada parte nombrará un árbitro y entre éstos se designará al tercero que presidirá el tribunal arbitral.

\footnotetext{
Ibid., p. 1785. Park expresamente indica que la fijación de la relación jurídica respecto de la cual se arbitrarán los conflictos no debe implicar la determinación exacta de los términos de la controversia, ya que ello se hará ante los árbitros.

Garcia Rubio, María Paz, op. cit., p. 74. Explica la autora que "la exigencia de determinación [de la relación jurídica] conlleva la invalidez del acuerdo de arbitraje relativo a relaciones meramente materiales o económicas o el referido genéricamente a cualquier asunto que pueda surgir entre las partes en el futuro, por implicar, este último, una renuncia general a la acción judicial".

Para cumplir con los requisitos esenciales indicados, bastará la redacción de un convenio arbitral, como el siguiente: «Cualquier litigio, controversia o reclamación provenientes de o relacionados con este contrato, así como cualquier caso de incumplimiento, terminación o invalidez del mismo, deberá ser resuelto por medio de arbitraje [...]» (Esta cláusula arbitral es la recomendada por la Comisión Interamericana de Arbitraje Comercial (CIAC).)

31 ReDFern, Alan, y Martin HUNTER, Law and Practice of International Commercial Arbitration, 2." ed., Sweet \& Maxwell, Londres, 1991, pp. 165-171.
} 
c) Lugar del arbitraje.- Si las partes no lo pactan, normalmente las leyes establecen en forma supletoria la forma de determinarlo o dejan el tema en manos de los árbitros.

d) Arbitraje de derecho o de equidad.- Las leyes optan por uno de estos dos tipos de arbitraje, a falta de pacto entre las partes.

e) El procedimiento arbitral.-Siendo el arbitraje un procedimiento de resolución de conflictos basado esencialmente en la autonomía de la voluntad de las partes, generalmente las leyes reconocen en las partes la facultad de establecer su propio procedimiento arbitral. A falta de acuerdo, la ley suele trasladar esta facultad a los árbitros o determinar un procedimiento supletorio.

f) Renuncia a la apelación.- En aquellas legislaciones que reconocen la facultad de acudir en apelación ante las cortes, normalmente se permite su renuncia.

g) Costos del proceso.- La ley suele establecer normas supletorias para determinar los costos del arbitraje, a falta de pacto entre las partes.

Como podemos apreciar, la figura del "convenio arbitral» permite a las partes acceder al arbitraje directamente, sin la necesidad de suscribir previamente un compromiso arbitral. Esto, como veremos enseguida, elimina la intromisión del Poder Judicial en esta etapa del arbitraje.

\section{2 ¿Cómo se ejecuta un convenio arbitral una vez surgida la controversia?}

Aquí caben hasta siete posibilidades, dependiendo de si el convenio arbitral se suscribe antes o después de que nazca la controversia, de si el arbitraje es institucional o ad hoc, y en este último caso, de si existe entidad nominadora de árbitros. Analicemos rápidamente cada supuesto por separado ${ }^{32}$.

\subsubsection{Convenio arbitral suscrito antes de surgir la controversia, sujeto a la administración de una institución arbitral}

En este caso, como existe una institución arbitral, bastará que al surgir la controversia el interesado presente la información requerida por el reglamento arbitral respectivo.

\footnotetext{
32 Sobre el tema recomendamos leer: Cantuarias S., Fernando, y Manuel Diego Aramburú Y., op. cit., pp. 148-158.
} 
El reglamento arbitral determinará la forma como debe procederse a la designación de los árbitros, regulará la manera como deben plantearse las pretensiones de las partes y establecerá todas las normas procedimentales pertinentes.

De esta manera, con un simple convenio arbitral suscrito antes de que nazca la controversia, sujeto a la administración de una institución arbitral, las partes podrán acudir a arbitrar directamente sus conflictos, sin tener que suscribir o integrar un nuevo contrato, ni acudir al juez.

\subsubsection{Convenio arbitral suscrito antes de surgir la controversia, sujeto a una entidad nominadora de árbitros (opcional: la sumisión a un reglamento arbitral)}

En este caso, aun cuando se trata de un arbitraje ad hoc, cuando nazca la controversia, a la parte interesada le bastará solicitar a la entidad nominadora (que puede ser, por ejemplo, el colegio de abogados de la localidad o cualquier tercero) que proceda a designar a los árbitros ${ }^{33}$. Nombrados los árbitros, si además las partes han incorporado a su convenio arbitral algún reglamento arbitral, el proceso arbitral se regulará de conformidad con dicho reglamento ${ }^{34}$. Caso contrario, y dependiendo de la legislación arbitral aplicable, el proceso será regulado por los árbitros o por las normas supletorias de la propia ley arbitral.

De esta manera, cuando se ha designado una entidad nominadora y ella cumple con el encargo, no habrá necesidad de suscribir o integrar un nuevo contrato y menos acudir al juez.

33 Cremades, Bernardo María, "España estrena nueva ley de Arbitraje", Revista de la Corte Española de Arbitraje, vol. V, Editorial Civitas, Madrid, 1988-1989, p. 37. "Al contrario que en el arbitraje institucional, donde existe un organismo competente [...] que a solicitud de una de las partes, cumple una serie de funciones -como la designación de árbitros-cuando la otra parte no lo hace, las reglas "ad hoc" establecen una "autoridad designadora", que puede ser una institución o persona dispuesta a actuar como tal.»

En este caso pueden presentarse innumerables posibilidades, ya que las partes pueden pactar, por ejemplo, que los tres árbitros serán nombrados por el tercero designador, o que cada parte nombrará un árbitro y el tercero sólo nombrará al presidente del tribunal arbitral, o que este tercero sólo actuará en caso de que alguna de las partes incumpla con designar a su árbitro, etc.

34 Las partes pueden acordar, por ejemplo, que el reglamento de Arbitraje del Centro de Arbirraje Nacional e Internacional de la Cámara de Comercio de Lima se aplicará a su arbitraje. En este caso, si bien el arbitraje no es institucional (ya que la Cámara de Comercio no lo va a administrar), los árbitros, en el arbitraje ad hoc que se siga, deberán aplicar el reglamento de arbitraje antes indicado, ya que las partes así lo decidieron. 


\subsubsection{Convenio arbitral suscrito antes de surgir la controversia, basado exclusivamente en el pacto de las partes}

Éste es el típico arbitraje ad hoc que normalmente genera graves problemas, ya que al no existir una entidad administradora del arbitraje (arbitraje institucional) ni una entidad nominadora de árbitros, cuando surja la controversia será necesario que las partes se pongan de acuerdo en la designación de los árbitros ${ }^{35}$, y, si ello no ocurre, normalmente habrá que acudir al juez.

Pero fijémonos que aquí la intervención del juez se va a dar siempre y cuando no se haya pactado un arbitraje institucional o no exista o se haya negado a actuar una entidad nominadora de árbitros o cuando las partes no se hayan puesto de acuerdo en la designación de los árbitros. Es decir, en este caso el juez actuará como una entidad nominadora residual de árbitros, cuya única función será la de colaborar en la designación de los árbitros faltantes. De esta manera el juez no otorgará ni integrará un convenio arbitral; es más, el juez prácticamente no podrá negarse a cumplir este encargo y jamás determinará la materia controvertida ${ }^{36}$.

Una vez instalado el tribunal arbitral, el proceso se regirá por las normas acordadas por las partes $\mathrm{y}$, a falta de aquéllas, por lo que dispongan los árbitros o la ley de la materia.

\subsubsection{Convenio arbitral suscrito una vez que ha surgido la controversia, sujeto a la administración de una institución arbitral}

En este caso las cosas son muy simples, ya que las partes al estar de acuerdo en acudir al arbitraje para resolver sus actuales conflictos, generalmente designarán a los árbitros y determinarán de antemano la materia en disputa, dejando todo lo demás a cargo del reglamento arbitral de la institución administradora del arbitraje.

Obviamente en este caso no habrá que ir al juez para nada.

\footnotetext{
35 Generalmente las leyes arbitrales modernas establecen que, a falta de acuerdo entre las partes, los árbitros serán tres. Asimismo disponen que a falta de acuerdo entre las partes acerca del sistema de designación de los árbitros, cada una designará un árbitro y entre éstos se nombrará al tercero que presidirá el tribunal arbitral.

Fijémonos que si resulta de aplicación este sistema supletorio, puede suceder que el juez que intervenga únicamente tenga que designar al árbitro de una de las partes, ya que la otra parte (la que requirió) necesariamente debió designar previamente a su árbitro, y el tercer árbitro deberá ser designado por los otros dos árbitros.

36. Ver infra, punto n. ${ }^{\circ} 4.3$.
} 


\subsubsection{Convenio arbitral suscrito una vez surgida la controversia, sujeto a una entidad nominadora (opcional: la sumisión a un reglamento arbitral)}

Este supuesto es difícil que se presente, ya que cuando las partes pactan la sumisión al arbitraje existiendo el conflicto, generalmente ellas mismas designan directamente a los árbitros. Sin embargo, nada obsta para que soliciten la intervención de un tercero para que cumpla con dicho encargo.

Nombrados los árbitros, el proceso será el mismo que el indicado en el punto 2.2.2 supra. Aquí tampoco intervendrá para nada el Poder Judicial.

\subsubsection{Convenio arbitral suscrito una vez surgida la controversia, basado exclusivamente en el pacto de las partes}

Este típico arbitraje ad hoc tampoco debería generar problemas, ya que las partes al pactar en este momento el arbitraje, se supone que cuidarán de designar a los árbitros. Sin embargo, si no lo hacen, ese hecho no obligará a la suscripción de un nuevo contrato (como sucedía con la figura del compromiso arbitral) o a la «integración» del convenio arbitral (como sucedía con la LGA derogada). Lo que sí podrá pasar es que si las partes no se ponen de acuerdo para designar a los árbitros, habrá que acudir a la entidad nominadora residual de árbitros dispuesta por la ley. En todo caso, esta situación difícilmente se presentará, ya que ambas partes voluntariamente desean acudir al arbitraje.

Luego de designados los árbitros, se seguirá el trámite indicado en el punto 2.2.3 supra.

\subsubsection{Convenio arbitral suscrito con anterioridad al nacimiento de la controversia y que luego de presentado el conflicto es ampliado y/o modificado por las partes}

Imaginemos que " $A$ » $y$ «" suscriben un convenio arbitral (sea institucional, con entidad nominadora o ad hoc) al momento de otorgar un contrato de compraventa $\mathrm{y}$, adicionalmente a los elementos esenciales del convenio arbitral ${ }^{37}$, acuerdan algunas disposiciones relativas al pro-

37 Ver supra, punto n. 2.1 
cedimiento arbitral. Sin embargo, al presentarse la controversia las partes desean modificar las normas de procedimiento por no ser las adecuadas para la resolución del conflicto surgido. ¿Es posible esto? ¿Estaremos ante una nueva relación jurídica?

Si aplicamos el criterio tradicional de cláusula-compromiso, el acuerdo previo al conflicto (cláusula) sólo tiene el efecto de obligar a suscribir un nuevo contrato (compromiso), el cual, como hemos indicado anteriormente, es indispensable para acudir al arbitraje. En cambio, con el criterio moderno de convenio arbitral, como este acuerdo existe y surte todos sus efectos desde que se otorga en la forma de cláusula, cualquier nuevo contrato que se suscriba no implicará la creación de una nueva relación jurídica, sino que, como bien indica la doctrina y la práctica arbitral, supondrá simplemente un agregado o modificación de la relación jurídica original, respecto de aquello no pactado en su momento o modificado por este nuevo acuerdo de voluntades ${ }^{38}$. En otras palabras, el nuevo acuerdo de voluntades no será obligatorio y de existir sólo será considerado como una ampliación o modificación del pacto previo, el cual por sí solo hubiera bastado para arbitrar directamente las controversias $^{39}$.

38 Graig, W. Laurence, Park, William, y Jan Paulsson, International Chamber of Commercial Arbitration, ICC Publishing, Paris, 1990, p. 49. «[...] it is not infrequent even where ICC arbitration has been stipulated in the contract, that the parties reach agreement after a given dispute has arisen with respect to certain particulars of the proceedings (place of arbitration, identity of the Chairman, mutually convenient procedural rules, and the like). Such agreements may better conform to the specific character of the case having arisen that the original arbitration clause. They are perfectly valid (after all, the parties could at any time agree to cancel the arbitration clause and bring the matter before an ordinary court). They are more realistically defined as amendments to the arbitration clause rather than as special submissions reflecting a partial novation of the arbitration clause. The new agreement will relate to modalities rather than the principle of arbitration [...].»

39 Como el convenio arbitral existe, es oponible y permite acudir directamente al arbitraje desde que es suscrito en la forma de cláusula, las partes, al saber que no pueden escaparse del arbitraje (como sí sucede en el caso de que haya que ir al juez para que otorgue el compromiso o «integre» el convenio), tienen todos los incentivos para que, cuando surja la controversia, se sienten en la mesa de buena fe y traten de que el arbitraje se lleve a cabo de la mejor manera posible. Éste es otro de los grandes beneficios del convenio arbitral.

Graig, W. Laurence, Park, William, y Jan Paulsson, op. cit., p. 49. "[...] it is because the parties know they cannot escape arbitration that they both have an incentive to make the experience as painless as possible.m 


\section{Contenido y ejecución del convenio arbitral en la derogada ley general de Arbitraje (decreto ley 25935)}

El artículo 10 de la derogada LGA regulaba los requisitos esenciales del convenio arbitral nacional ${ }^{40}$. Esta norma, como puede verificarse de una simple lectura, exigía no sólo los elementos que la doctrina y legislación comparada reconocen como esenciales para la existencia del convenio arbitral (es decir, el pacto expreso de las partes de acudir al arbitraje y la fijación de la relación jurídica respecto de la cual se arbitrarán las controversias), sino que, además, disponía la necesidad de nombrar a los árbitros (o fijar la forma de nombramiento de éstos) y la determinación de la controversia (o el traslado de esta responsabilidad a los árbitros), entre otros.

Los requisitos exigidos por la derogada LGA en cuanto al contenido mínimo del convenio arbitral, no sólo eran muy similares a los que las derogadas disposiciones del Código Civil demandaban para la configuración del contrato de compromiso arbitral ${ }^{41}$, sino que, además, y ello era lo más preocupante, los efectos de una cláusula compromisoria regida por las disposiciones del Código Civil, como de un convenio arbitral incompleto regulado por la derogada LGA, resultaron siendo prácticamente los mismos. Veamos: antiguamente, cuando existía una cláusula compromisoria y surgía una controversia, la parte interesada si no lograba que la otra parte suscribiera un compromiso arbitral nombrando a los árbitros y determinando la controversia, tenía que ir al juez para que éste otorgara dicho contrato en rebeldía. Lo mismo sucedió en aplica-

41" "Artículo 10.- El convenio arbitral debe contener, como minimo:

1.- Nombres de las partes y de los árbitros, o indicación del procedimiento de designación de éstos, o referencia expresa a la institución que, de acuerdo a sus reglamentos, organizará el arbitraje y designará a los árbitros;

2.- La controversia que se somete a decisión arbitral. Sin embargo, las partes pueden deferir la determinación de la controversia a la institución organizadora del arbitraje a cuyo reglamento preestablecido se hubieran sometido, o facultar a los árbitros para que la determinen;

3.- El lugar donde debe desarrollarse el arbitraje. A falta de estipulación, se entiende que será el lugar que los árbitros decidan, o el fijado por la entidad organizadora del arbitraje;

4.- El plazo de duración del proceso arbitral. A falta de estipulación o de referencia a un reglamento arbitral, el plazo máximo es de ciento veinte días hábiles, contados desde la aceptación del árbitro o de la instalación del tribunal arbitral.»

4ı Artículo 1911 del Código Civil de 1984: «El convenio arbitral contendrá:

1.- El nombre y domicilio de los otorgantes y de los árbitros. Si el árbitro designado fuese una persona jurídica se indicará su denominación o razón social y domicilio.

2.- La controversia que se somete al fallo arbitral, con expresión de sus circunstancias.

3.- El plazo en que los árbitros deben pronunciar el laudo.

4.- El lugar en que debe desarrollarse el arbitraje." 
ción de la derogada LGA, ya que si al convenio arbitral le faltaba la designación de los árbitros y la materia controvertida, de conformidad con el artículo 13 de dicha LGA, el interesado tenía que solicitar la colaboración de la otra parte para determinar la materia controvertida y designar a los árbitros, y si no lo lograba, pues tenía que acudir al juez para que éste "integrara" los elementos faltantes del convenio arbitral (artículo 15 LGA derogada) ${ }^{42}$. De esta manera, el interesado tenía que acudir al juez tal y como sucedía anteriormente cuando estaba vigente el contrato de compromiso arbitral (Código Civil de 1984) ${ }^{43}$.

Otro efecto pernicioso que generaban los artículos 10,13 y 15 de la derogada LGA, estaba referido a los supuestos en los que se podía basar el juez para denegar un pedido de «integración» del convenio arbitral. Veamos: imaginemos que " $A$ " ante la negativa de " $B$ " (empresa aseguradora) de integrar el convenio arbitral (art. 13), solicita al juez tal integración al amparo del artículo 15 de la derogada LGA. "A" le indica al juez que la materia controvertida estará referida a problemas suscitados en el pago de un siniestro, el cual en su opinión no fue cancelado íntegramente. «B», la compañía de seguros, se apersona al proceso y se opone a la «integración" afirmando que en su momento pagó y "A» no se opuso a tal pago, por lo que no existe materia alguna en conflicto. ¿Cómo debía resolver el juez en base a la derogada LGA? Como veremos más adelan$\mathrm{te}^{44}$, si la LGA derogada hubiera incorporado realmente la figura del convenio arbitral, el juez jamás hubiera tenido que integrar un contrato, sino limitar su intervención, en algunos casos, a actuar como entidad nominadora residual de árbitros sin entrar a determinar la materia controvertida.

42 Es cierto que la derogada LGA indicaba que el juez ya no "otorgaba" un nuevo contrato en rebeldia de las partes, sino que "integraba" el mismo contrato. Sin embargo, palabras más palabras menos, lo cierto es que el juez intervenía tal y como lo hacía en aplicación de las normas derogadas del Código Civil.

Lohmann Luca de Tena, Juan G., "Ley general de Arbitraje, unas glosas de urgencia” (en adelante simplemente "Glosas"), Informativo Legal Rodrigo, n. ${ }^{\circ}$ 80, Lima, 1993, p. 2.9. El autor indica lo siguiente, en referencia a la derogada LGA: «el nuevo régimen legal [...] posibilita generosamente la eficacia del acuerdo arbitral [...] pues si las partes fracasan en coincidir sobre sus elementos, éstos podrán ser integrados por el juez, para lo que existe un trámite judicial más expeditivo que el anteriorm.

Verifiquemos cómo, para este autor, que fue uno de los ponentes principales de la derogada LGA, el cambio del sistema de cláusula-compromiso a convenio arbitral tuvo únicamente un efecto "cuantitativo"; es decir, a partir de la vigencia de la derogada LGA, el trámite judicial era simplemente "mas expeditivo que el anterior". Olvidó sin embargo el autor, que el principal efecto de incorporar realmente la figura del convenio arbitral es "cualitativo", en el sentido de que a partir de su vigencia jamás el Poder Judicial otorgará o integrará un convenio arbitral, simplemente porque éste está completo desde que se suscribe en la forma de cláusula.

44 Ver infra, punto n." 4.3. 
Dentro de este contexto, en el presente caso el juez sólo hubiera podido negarse a nominar a los árbitros faltantes, si es que no se hubiera demostrado la existencia del convenio arbitral ${ }^{45}$.

En cambio, siendo que en la LGA derogada el juez «integraba» un convenio arbitral, con el nombre de los árbitros y la materia controvertida, el magistrado tendía a verificar si existía o no controversia, por lo que si, en el caso planteado, el juez consideraba que ya se había pagado, podía negarse a amparar el pedido de integración. Según nos han informado varios colegas, esta situación se presentó en un proceso de integración seguido por un asegurado contra una compañía de seguros, en el que algunas instancias del Poder Judicial se negaron a amparar la integración solicitada bajo el argumento de que no existía controversia alguna porque el asegurado había recibido el pago sin reserva. Obviamente esta situación resulta inaceptable si se quiere promover la utilización del arbitraje.

Éstos y otros problemas identificados en la anterior LGA se debieron a una deficiente regulación legal ${ }^{46}, y$ en la práctica conllevaron a que se avanzara muy poco con respecto a la anticuada legislación arbitral contenida en el Código Civil de 1984. Obviamente esta situación motivó la urgente modificación legislativa que se acaba de producir hace unos días con la dación de la nueva LGA.

\section{Contenido y ejecución del convenio arbitral en la nueva ley general de Arbitraje, ley 26572}

La nueva LGA define correctamente al convenio arbitral como el acuerdo por el que las partes deciden someter a arbitraje las controversias que hayan surgido o puedan surgir entre ellas respecto a una determinada relación jurídica contractual o no contractual (arts. 9 y 98 LGA). De esta manera, independientemente del momento en que se suscriba el

\footnotetext{
45 Esta sabia disposición se encuentra contemplada en el inciso 1) del artículo 42 de la ley de Arbitraje española de 1988, que a la letra dice: "Art. 42.- 1. El juez únicamente podrá rechazar la formalización judicial del arbitraje cuando considere por los documentos aportados que no consta de manera inequívoca la voluntad de las partes."

La norma es absolutamente coherente, ya que si el juez sólo interviene en algunos casos como entidad nominadora residual de árbitros, él no puede negarse a cumplir tal encargo, salvo si no se prueba la existencia del convenio arbitral.

46 Cantuarias S., Fernando, y Manuel Diego Aramburú Y., op. cit. En este libro los autores analizamos los diversos errores detectados en la derogada LGA, proponiendo al mismo tiempo las correspondientes correcciones.
} 
acuerdo arbitral (antes o después de surgida la controversia), sólo existirá un contrato: el convenio arbitral.

De la propia definición que da la LGA pueden desprenderse claramente los requisitos esenciales del convenio arbitral, siendo éstos: 1) La decisión de las partes de pactar el arbitraje, y 2) La determinación de la relación jurídica respecto de la cual se arbitrarán los actuales o potenciales conflictos.

De esta manera, elementos que la anterior LGA consideraba como esenciales y que previamente al arbitraje debían ser «integrados" (árbitros y materia controvertida), desaparecen definitivamente, convirtiéndose en supuestos a los que se arribará en ejecución del convenio arbitral, tal y como demostraremos a continuación.

\subsection{Convenio arbitral suscrito antes de surgir la controversia, sujeto a la administración de una institución arbitral}

El artículo 6 de la LGA establece que «la organización y desarrollo del arbitraje pueden ser encomendados a una institución arbitral [... la cual] estará facultada para nombrar a los árbitros, así como para establecer el procedimiento y las demás reglas a las que se someterá el arbitraje, de conformidad con su reglamento arbitral" ${ }^{47}$.

Para acceder a un arbitraje institucional bastará para el efecto apelar a las cláusulas arbitrales tipo que las instituciones arbitrales recomiendan. Así, por ejemplo, tenemos la sugerida por el Centro de Arbitraje Nacional e Internacional de la Cámara de Comercio de Lima:

"Todas las desavenencias o controversias que pudieran derivarse de este contrato, incluidas las de su nulidad o invalidez, serán resueltas mediante fallo definitivo e inapelable, de conformidad con los reglamentos de conciliación y arbitraje del Centro de Arbitraje Nacional e Internacional de la Cámara de Comercio de Lima, a cuyas normas las partes se someten en forma incondicional. $»^{48}$.

\footnotetext{
47 En la sección correspondiente al arbitraje internacional no existe una disposición tan clara como la dispuesta en el artículo 6 de la LGA. Sin embargo, las mismas facultades se desprenden de los incisos 3) y 4) del artículo 93 de la LGA.

${ }_{48}$ El Centro de Arbitraje Nacional e Internacional de la Cámara de Comercio de Lima tiene su sede en la avenida Gregorio Escobedo, n. ${ }^{0}$ 398, Jesús María.
} 
En caso surja una controversia, la parte interesada deberá presentar a la institución arbitral un documento conteniendo los requisitos exigidos en el reglamento arbitral respectivo. La designación de los árbitros, la manera de presentar las pretensiones, así como los demás temas relacionados con el arbitraje, se determinarán de conformidad con el reglamento arbitral correspondiente.

De esta forma, aun habiendo las partes suscrito un acuerdo arbitral antes de que nazca la controversia, no será necesario suscribir o integrar contrato alguno y menos tener que acudir al Poder Judicial. Simplemente, el Poder Judicial no intervendrá más.

\subsection{Convenio arbitral suscrito antes de surgir la controversia, sujeto a una entidad nominadora de árbitros (opcional: la sumisión a un reglamento arbitral)}

Como indicamos anteriormente ${ }^{49}$, si bien éste es un arbitraje ad hoc, las partes pueden nombrar en su convenio arbitral a una o más personas para que procedan únicamente a designar a alguno o a todos los árbitros, sea de manera directa o en defecto de las partes ${ }^{50}$.

Generalmente las partes designarán para cumplir este encargo a una institución arbitral ${ }^{51}$ o a una entidad gremial, como puede ser el Colegio de Abogados de Lima ${ }^{52}$.

Nombrados los árbitros por las partes y/o por la entidad nominadora, si además las partes han incorporado a su convenio arbitral algún reglamento arbitral de alguna institución arbitral, el proceso arbitral, aun cuando siempre será ad hoc, se regulará de conformidad con dicho reglamento como si sus reglas hubieran sido pactadas expresamente por las partes ${ }^{53}$. Caso contrario, el proceso será determinado por los árbitros, dentro del marco legal dispuesto por la $\mathrm{LGA}^{54}$.

\footnotetext{
49) Ver supra, punto n. ${ }^{\circ} 2.2 .2$.

50) Artículo 20 de la LGA: "Los árbitros serán designados por las partes o por un tercero, quien puede ser persona natural o jurídica, incluida una institución arbitral.»

51 Cuarta Disposición Complementaria y Transitoria de la LGA: «Las instituciones arbitrales deberán incorporar dentro de sus reglamentos arbitrales, disposiciones referidas a su actuación como entidades nominadoras de árbitros."

52 Ver supra, cita n." 33.

53. Ver supra, cita n. ${ }^{\circ} 34$.

54 Los artículos 33 y 108 de la LGA reconocen amplia libertad en las partes y, en su defecto, en los árbitros, para que determinen las reglas del proceso arbitral, dentro del marco mínimo dispuesto en la propia LGA. Este marco básicamente requiere que se trate a las partes con igualdad y que se dé a cada una plena oportunidad de hacer valer sus derechos. El proceso arbitral
} 
De esta manera, aun cuando las partes hayan pactado un arbitraje ad hoc antes de que surja la controversia, existiendo entidad nominadora de árbitros que cumpla con su función jamás será necesario otorgar o integrar un nuevo contrato y menos acudir al juez.

\subsection{Convenio arbitral suscrito antes de surgir la controversia, basado exclusivamente en el pacto de las partes}

Como indicamos anteriormente ${ }^{55}$, en este caso sí pueden presentarse problemas al momento de ejecutarse el convenio arbitral, ya que el arbitraje no es institucional y tampoco existe entidad nominadora de árbitros.

El problema principal se da al momento en que surge la controversia y una de las partes (obviamente, la interesada en que se active el arbitraje) requiere a la otra parte para que, de conformidad con el pacto de las partes ${ }^{56} \mathrm{o}$, en su defecto, de acuerdo con las disposiciones supletorias de la $\mathrm{LGA}^{57}$, proceda a la designación de los árbitros, negándose esta última a colaborar.

Ante la inexistencia de un arbitraje institucional (en el que, de conformidad con su reglamento arbitral, siempre se designarán a los árbitros) y ante la carencia de una entidad nominadora de árbitros ${ }^{58}$, el arbitraje se paralizaría si la LGA no estableciera una entidad nominadora residual de árbitros, la cual legalmente tuviera la facultad de imponer a los árbitros faltantes y de esa manera constituir debidamente el tribunal arbitral. Justamente, para evitar la paralización del arbitraje, el artículo 23 ubicado en la sección sobre arbitraje nacional dispone que la entidad nominadora residual de árbitros será el juez de primera instancia al que

necesariamente deberá tener tres etapas: la alegatoria (en la que las partes presentan sus pretensiones); la probatoria (en la que se actúan las pruebas), y la decisoria (en la que se emite el laudo arbitral).

55 Ver supra, punto n. ${ }^{\circ} 2.2 .3$.

56. Los artículos 21 y 101 de la LGA expresamente establecen que las partes podrán determinar libremente el procedimiento de designación de los árbitros. Esta libertad tiene como única condición que se respete el principio de igualdad de las partes. Es decir, cualquiera sea el sistema dispuesto por las partes, éste no puede autorizar a que una de ellas designe a todos o a la mayoría de los árbitros, siendo cualquier estipulación en ese sentido nula, de conformidad con el último párrafo del artículo 14 de la LGA.

57 Si las partes no se han sometido a un arbitraje institucional o no han pactado el procedimiento de designación de árbitros, los artículos 21 y 102 de la LGA establecen un sistema supletorio mediante el cual cada parte nombrará un árbitro y los dos árbitros así designados nombrarán al tercero, quien presidirá el tribunal arbitral.

${ }_{58} \quad$ Ver supra, puntos n. ${ }^{\text {os }} 2.2 .2$ y 4.2 . 
las partes se hubieran sometido expresamente, o, en su defecto, el de la sede del arbitraje o, a falta, el del lugar del domicilio del emplazado.

Pero aquí resulta de fundamental importancia comparar el sistema dispuesto por la nueva LGA, con el establecido en el anterior marco normativo. En aplicación de la anterior LGA, aun cuando las partes hubieran pactado el arbitraje, surgida la controversia la parte interesada estaba obligada a remitir a la otra parte una carta notarial proponiéndole el nombre de todos los árbitros y la determinación de la materia controvertida (art. 13 LGA derogada). Si las partes no se ponían de acuerdo había que iniciar una demanda judicial de «integración» del convenio arbitral (art. 15 LGA derogada), demanda en la que se discutía la pertinencia de integrar un contrato. Este pleito podía llegar a la Corte Suprema de la República, pudiendo suceder incluso que el Poder Judicial se negara a la «integración» famosa por diversos motivos. Así, en el mejor de los casos, después de varios años de litigio, si el Poder Judicial amparaba la solicitud de integración, recién en ese momento el juez imponía a todos los árbitros y, lo que era más dramático aún, determinaba la materia que se sometería al arbitraje. Obviamente, este trámite era absurdo.

Con la nueva LGA, al juez se acude exclusivamente en busca de ayuda en el caso de que no se haya podido designar a todos los árbitros, correspondiéndole únicamente la función de nombramiento de los árbitros que falten designar. Es decir, ahora el juez actúa de la misma manera como actuaría una entidad nominadora de árbitros dispuesta contractualmente, mediante un simple trámite que no tiene la calidad de un proceso judicial (no hay litis alguna) y que por ello no es apelable ${ }^{59}$. Obviamente dentro de este proceso no corresponde determinar materia controvertida alguna y, por tanto, tampoco corresponde que el juez se niegue a cumplir el encargo apelando a cuestiones referidas a la materia que se pretende arbitrar ${ }^{60}$.

Es más, la LGA ha establecido que, tratándose de arbitrajes internacionales, la entidad nominadora residual de árbitros será cualquiera de las instituciones arbitrales ubicadas en el lugar donde deba realizarse el arbitraje o de las ubicadas en Lima, a elección del interesado (art. 102

59 La apelación, sin embargo, sí está reconocida en el inciso 8) del artículo 23 de la LGA, pero únicamente para aquellos casos en que el juez se niegue a cumplir con su función de entidad nominadora residual de árbitros. Ver infra, cita n. ${ }^{\circ} 60$.

(1) El juez no puede negarse a cumplir con el encargo, salvo que considere, por los documentos aportados por las partes, que no consta la voluntad de las partes de acudir al arbitraje (inciso 5) del artículo 23 de la LGA). Siendo que el artículo 9 de la LGA establece que el convenio debe ser celebrado por escrito, el juez únicamente podría rechazar la solicitud si no se presenta el convenio arbitral por escrito. 
LGA). De esta manera, en los arbitrajes internacionales no será necesario en estos casos acudir al auxilio del Poder Judicial ${ }^{61}$.

Una vez designado el tribunal arbitral, sea directamente por las partes o apelando al auxilio del Poder Judicial o de una institución arbitral, dependiendo de que el arbitraje sea nacional o internacional, el proceso se regirá por las normas acordadas por las partes o, en su defecto, por lo que dispongan los árbitros, siempre dentro del marco de la LGA.

\subsection{Convenio arbitral suscrito una vez que ha surgido la controversia, sujeto a la administración de una institución arbitral}

Aquí obviamente es de aplicación lo indicado en el punto 4.1 supra, no siendo necesaria la intervención del Poder Judicial.

Cabe sin embargo aclarar que, siendo que en este momento ya se conoce la controversia y las partes están dispuestas a recurrir al arbitraje, lo razonable es que designen a los árbitros ${ }^{62}$ y determinen la materia controvertida ${ }^{63}$. Sin embargo, si no lo hacen no pasa nada, ya que los árbitros serán designados y la materia será determinada, de conformidad con las disposiciones arbitrales reglamentarias, dentro del arbitraje iniciado ante la institución arbitral.

\subsection{Convenio arbitral suscrito una vez surgida la controversia, sujeto a una entidad nominadora (opcional: la sumisión a un reglamento arbitral)}

Como indicamos en su momento ${ }^{64}$, es difícil que las partes, pactando el arbitraje cuando ya conocen los extremos de la controversia, decidan diferir el nombramiento de todos o alguno de los árbitros a una entidad nominadora de árbitros, en vez de designarlos directamente.

\footnotetext{
61 El artículo 103 de la LGA establece que el Poder Judicial intervendrá sólo en caso de que las partes hayan expresamente decidido su participación para estos efectos.

62 Es razonable, porque ello evitará potenciales demoras mientras, en aplicación del reglamento arbitral, se corre traslado a las partes para que designen a sus árbitros. Sin embargo, es importante que, antes de proceder a la designación directa de los árbitros, se verifiquen las disposiciones arbitrales de la institución arbitral a la que se ha sometido el arbitraje, ya que algunas veces estas instituciones se reservan la designación de alguno de los árbitros o requieren que los árbitros cumplan con ciertos requisitos especiales.

${ }_{63}$ Es razonable que ambas partes determinen de común acuerdo la materia controvertida, por cuanto ello evitará que más adelante alguna de ellas impugne la competencia de los árbitros aduciendo que tal o cual materia no ha sido somerida al arbitraje.

64 Ver supra, punto n. ${ }^{\circ} 2.2 .5$.
} 
Sin embargo, si así lo acuerdan, habrá que esperar que la entidad nominadora nombre a los árbitros, luego de lo cual se instalará el tribunal arbitral y se iniciará el proceso arbitral, sin la necesidad de la intervención del Poder Judicial ${ }^{65}$.

\subsection{Convenio arbitral suscrito una vez surgida la controversia, basado exclusivamente en el pacto de las partes}

Como indicamos anteriormente ${ }^{66}$, si las partes quieren arbitrar sus actuales controversias lo razonable es que designen a los árbitros y determinen la materia controvertida. Sin embargo, si no nombran a todos los árbitros habrá que recurrir al Poder Judicial o a una institución arbitral, dependiendo de si el arbitraje es nacional o internacional, para que, actuando como entidades nominadoras residuales de árbitros, procedan a colaborar en la constitución del tribunal arbitral. Instalado que fuera el tribunal arbitral, la materia controvertida será determinada ante los árbitros, si es que ésta no fue previamente acordada por las partes en su convenio arbitral.

\section{A modo de conclusión}

La inclusión de la figura del convenio arbitral dentro del marco legal dispuesto por la nueva LGA implica un cambio cualitativo de suma importancia para el desarrollo de la práctica arbitral en nuestro país, por cuanto elimina el nefasto intervencionismo del Poder Judicial que se generaba con el otorgamiento del compromiso arbitral (Código de Procedimientos Civiles y Código Civil) o con la «integración» del convenio arbitral (LGA derogada), reservando la participación judicial únicamente para que auxilie en la designación de los árbitros faltantes. De esta manera, el Poder Judicial actuará, de ahora en adelante, en favor del arbitraje.

Esperamos que este cambio cualitativo, conjuntamente con otros que contiene la nueva LGA, posibiliten la consolidación de la práctica arbitral en nuestro país.

\footnotetext{
65 Obviamente existe el riesgo potencial de que la entidad nominadora no cumpla con el encargo. En ese caso, es de esperar que, como las partes quieren arbitrar sus controversias, procedan ellas mismas a nombrar a los árbitros faltantes. Caso contrario, en aplicación de los artículos 22 y 103 de la LGA, no quedará otro camino que recurrir al Poder Judicial o a una institución arbitral, dependiendo de que el arbitraje sea nacional o internacional.

66 Ver supra, citas n. ${ }^{\circ 6} 62$ y 63.
} 